\title{
Comparative in vitro antioxidant and antibacterial activities of leaf extract fractions of Crimson bottlebrush, Callistemon citrinus (Curtis.) Skeels
}

\author{
Poulomi Ghosh, Souren Goswami, Sujit Roy, Ria Das, Tista Chakraborty, Sanjib Ray*
}

Molecular Biology and Genetics Unit, Department of Zoology, The University of Burdwan, Golapbag, Purba Bardhaman-713104, West Bengal, India

*Corresponding author's Email address: sray@zoo.buruniv.ac.in

\begin{abstract}
Objectives: The present study aimed to analyze a comparative in vitro free radical scavenging and antibacterial potentials of leaf aqueous and the successive extract fractions of Callistemon citrinus. Methods: For in vitro antioxidant activity assessments, 1,1-diphenyl-2picrylhydrazyl (DPPH) free radical scavenging activity, $\mathrm{Fe}^{3+}$ ion reducing antioxidant power (FRAP) assay, and total antioxidant capacity of the extracts were tested. Antibacterial potentials were tested through Agar well diffusion method using both gram-positive and gram-negative bacterial strains. Results: Data indicate the polar successive aqueous fraction (AQF) possesses the highest free radicals scavenging capacity, with lowest $\mathrm{EC}_{50}$ (the required extract concentration to scavenge half of the free radicals) for DPPH and FRAP assays, and contains the highest total phenolics (308.2 $\pm 5.9 \mu \mathrm{g}$ tannic acid equivalent/mg dry extract, DE), flavonoids $(516.7 \pm 3.5 \mu \mathrm{g}$ quercetin equivalent/mg DE), total antioxidant capacity $(441.48 \pm 12.8 \mu \mathrm{g}$ ascorbic acid equivalent/mg DE). Phenolics and flavonoids contents were positively correlated with the in vitro antioxidant activities. The antibacterial study indicates the petroleum ether and chloroform are suitable solvents for extracting antibacterial phytochemicals from $C$. citrinus leaves that are effective against both gram-positive and negative bacterial strains. Conclusion: The most polar fraction i.e. the successive aqueous extract fraction of $C$. citrinus leaves exhibited the highest antioxidant activities while the most non-polar petroleum ether extract fraction showed the highest antibacterial potentials thus these extract fractions might have therapeutic importance.
\end{abstract}

Keywords: Antioxidant; Antibacterial; DPPH; FRAP; Phenolics. 


\section{List of abbreviations: \\ PEF- Petroleum ether fraction \\ CHF- Chloroform fraction \\ EAF- Ethyl acetate fraction \\ MEF- Methanol fraction \\ AQF- Aqueous fraction \\ CAQ- Crude aqueous extract \\ AAE- Ascorbic acid equivalent \\ TAE- Tannic acid equivalent \\ QE- Quercetin equivalent \\ TFC- Total flavonoids content \\ TPC- Total phenolics content \\ DMSO- Dimethyl sulfoxide \\ SEM-Standard error mean \\ SEF- Successive extract fractions \\ DE- Dried extract}

\section{Introduction}

In living cells, spontaneous production of a minimum level of free radicals is a normal physiological phenomenon, which is naturally maintained by in vivo antioxidant systems without causing any self-damage. This redox biology is very important to continue many physiological and biochemical actions, like cellular signaling in the host defense system ${ }^{1}$. The change in homeostasis between pro-oxidant and antioxidants leading to the pro-oxidant level high, moves towards oxidative stress. The reactive oxygen species (ROS), reactive nitrogen species (RNS), and their derivatives are produced in biological systems through the normal metabolic process and cause oxidative stresses while the endogenous counter mechanisms cannot balance those. Then we need to depend upon exogenous supplies through consuming antioxidant-rich foodstuffs or medicines to protect our body from their deleterious effects. Oxidative stress affects devastatingly on human health by inactivating the metabolic enzymes, damaging important cellular components, and oxidizing the proteins, nucleic acids, and lipids ${ }^{2,3}$. The standard antioxidant drugs like vitamin C, E, A, folic acid, gallic acid, etc. are mostly phenolics or flavonoids in nature. Antioxidants reduce the free radical burden of organisms by quenching them and thus they decrease the risk of oxidative stress-related pathologies ${ }^{4}$. Antioxidant quenches free radicals through several ways, like hydrogen-atom transfer (HAT) or singleelectron transfer (SET) or both, and also repressing ROS/RNS generation by silencing some enzymes or chelating trace metals involved in reactive species production ${ }^{1,2}$. Several scientific 
reports indicated antioxidant properties of the different plant parts (leaves, fruits, barks or bulbs) and a strong positive correlation with their phenolics and flavonoids contents $5,6,7,8,9,10$.

It was reported that the microbial species have been taken up approximately $60 \%$ of Earth's biomass, spread over nearly every habitat. Many of them are pathogenic and behind huge loss of human lives, livestock and crop productions. Overcrowded population is also a major reason to emerge and enhance in the infectious diseases over the last two decades. There are so many common broad and narrow-spectrum antibiotics such as amoxicillin, azithromycin, clindamycin, metronidazole, levofloxacin, tetracycline, kanamycin, etc. that are effective against both gram-negative and gram-positive bacteria, but these synthetic antibiotics show many side effects like increased oxidative stress, loss of appetite, diarrhea, indigestion or stomach pain ${ }^{11}$. Earlier reports are indicating that many plant extracts have rich antimicrobial as well as antioxidant properties ${ }^{8,12}$. Plant-derived natural compounds occupied a major portion of the pharmaceutical market just because of their fewer side effects, cost efficiency, and eco-friendly nature relative to the modern semi-synthetic or synthetic drugs.

Callistemon citrinus is an ornamental plant, mainly distributed in both the subtropical and tropical regions. It is commonly used in folk medicine to treat gastrointestinal pain, respiratory disorders, infectious diseases, etc. ${ }^{13,14}$. Scientific analysis revealed that this plant possesses antidiabetic, hypolipidemic, antioxidant ${ }^{15}$, cardioprotective $^{16}$, hepatoprotective ${ }^{17}$, antiHelicobacter pylori $^{18}$, calcium channel inhibitor ${ }^{19}$, anti-elastase ${ }^{20}$, wound healing, antithrombic ${ }^{21}$, anticholinesterase and anti-inflammatory ${ }^{15}$ activities. Jamzad et al. ${ }^{5}$, reported a significant in vivo antioxidant activity of its flower extract, correlating with its flavonoids and phenolics contents. They also found that, its hydro-methanolic (1:4) extracts have a higher free radical scavenging potential than its essential oils. The essential oil content of this plant constitutes of some volatile aromatic and odoriferous compounds like 1,8-cineole, $\beta$-thujone, limonene, capillene, $\alpha$-pinene, pulegone, $\beta$-pinene, etc. and are responsible for its bioactivities. Leaves and flowers of $C$. citrinus constitute a major compound, 1-(2,6-dihydroxy-4-methoxyphenyl)-3methylbutan-1-one (phloroglucinol) which was reported for potent dose-dependent antinociceptive and anti-inflammatory properties correlating its strong in vivo antioxidant activity $^{22}$. Different medicinal properties like thrombolytic, membrane-stabilizing, free radical 
scavenging and anti-inflammatory potentials of the different organic solvent-mediated leaf extracts of $C$. citrinus were studied and revealed to be very promising ${ }^{23}$.

Antibacterial potency of this plant was also evaluated. Its crude leaf ethanolic and $80 \%$ methanolic extract showed promising antimicrobial activity against gram-positive (Bacillus anthracis, Bacillus cereus, Streptococcus pyrogenes, and Listeria monocytogenes) and gramnegative (Salmonella typhi, Klebsiella pneumoniae, Escherichia coli, and Pseudomonas aeruginosa) bacterial strains ${ }^{24}$. Alkaloids, extracted from the leaves of $C$. citrinus were reported for bacterial growth inhibition with only 0.0025 and $0.835 \mathrm{mg} / \mathrm{mL}$ minimum bactericidal concentrations (MBC), respectively for Staphylococcus aureus and Pseudomonas aeruginosa ${ }^{25}$.

In the present state of knowledge, it is not clear about the antioxidant property of the crude leaf aqueous extract and the successive extract fractions of $C$. citrinus, and also their comparative in vitro antioxidant and antibacterial properties. Therefore, the present study was designed to analyze a comparative account of in vitro antioxidant and antibacterial activities of the leaf aqueous extract and the successive extract fractions of $C$. citrinus and to correlate these effects with their total phenolics and flavonoids contents.

\section{Materials and methods}

\subsection{Chemicals}

Glacial acetic acid and methanol were obtained from BDH Chemicals Ltd., UK. Ascorbic acid, DPPH, tannic acid, quercetin, and ferric chloride were purchased from Thermo Fisher Scientific Pvt. Ltd., Mumbai, India. Aluminum chloride, Muller Hinton agar, and Tetracycline were obtained from Himedia Laboratories Pvt. Ltd., Mumbai, India. Trichloroacetic acid (TCA) was purchased from Sigma Chemical Co, St.Louis, M.O. The USA. Sodium nitrite $\left(\mathrm{NaNO}_{2}\right)$, sodium hydroxide $(\mathrm{NaOH})$, sodium carbonate $\left(\mathrm{Na}_{2} \mathrm{CO}_{3}\right)$, disodium hydrogen phosphate $\left(\mathrm{Na}_{2} \mathrm{HPO}_{4}\right)$, dimethyl sulfoxide (DMSO) and Folin-Ciocalteu's phenol reagent were obtained from Merck Specialities Pvt. Ltd., Mumbai, India. The used other chemicals were of analytical grade. 


\subsection{Plant collection, authentication, and storage}

Fresh leaves of $C$. citrinus were collected from the Tarabag Residential Complex of The University of Burdwan. Prof. A. Mukherjee, Department of Botany, The University of Burdwan, has authenticated the plant taxonomically and a voucher specimen (No. BUR/TB/PG/01) is being preserved in the Department of Zoology. The collected leaves were washed thoroughly with tap water, shade dried, crushed into small pieces, made it into powder form with an electrical grinder (Philips Mixer blender HL 1605), and stored in an airtight glass container for future use.

\subsection{Extracts preparation}

$20 \mathrm{~g}$ ground leaf of $C$. citrinus was extracted in $400 \mathrm{~mL}$ of distilled water at $80^{\circ} \mathrm{C}$ in a water bath and at every $4 \mathrm{~h}$, the extract was collected and filtered through No. 1 Whatman filter paper. This process was repeated 3 times to get a large quantity of crude aqueous extract (CAQ) and it was then concentrated using a vacuum evaporator and stored at $-20^{\circ} \mathrm{C}$ for future use.

Another $50 \mathrm{~g}$ of the leaf powder was successively extracted using a Soxhlet apparatus for $72 \mathrm{~h}$ with the different organic solvents $(600 \mathrm{~mL})$ of increasing polarity like petroleum ether, chloroform, ethyl acetate, methanol and distilled water at their boiling point. After every extraction, the remaining leaf powder was dried properly to remove the trace of organic solvents. All the extracts were then filtered through Whatman filter paper no. 1. and the successive extract fractions (SEF) [PEF; petroleum ether fraction, CHF; chloroform fraction, EAF; ethyl acetate fraction, MEF; methanol fraction, AQF; aqueous fraction] were dried completely using a rotary vacuum evaporator. Finally, these dried extract fractions were stored in airtight glass containers at $4^{\circ} \mathrm{C}$ for future use.

For in vitro antioxidant assays and quantitative phytochemical analysis the PEF, CHF, EAF, and MEF were dissolved in methanol, and AQF was dissolved in distilled water. For antibacterial assay PEF, CHF, and EAF were dissolved in $0.1 \%$ DMSO solution and MEF, AQF was dissolved in autoclaved distilled water.

\subsection{In vitro antioxidant activity assessment}

\subsubsection{DPPH free radical scavenging assay}

The in vitro free radical scavenging activity of leaf aqueous extract and the SEF of $C$.

citrinus leaves were determined through DPPH scavenging assay ${ }^{26}$. The standard ascorbic acid and different extract fractions $(0.5 \mathrm{~mL}$ each) were taken in the respective test tubes and then 0.25 
$\mathrm{mL}$ freshly prepared $1 \mathrm{mM}$ DPPH methanolic solution and $1.5 \mathrm{~mL}$ of methanol was added to each. The test tubes were incubated for $35 \mathrm{~min}$, in dark at room temperature $\left(25 \pm 2^{\circ} \mathrm{C}\right)$ and then the optical density (OD) was measured at $517 \mathrm{~nm}$ using a UV-Vis spectrophotometer (UV-1800 Series, Shimadzu, Japan). A freshly prepared ascorbic acid solution of different concentrations (5-30 $\mu \mathrm{g} / \mathrm{mL})$ was used to prepare the standard curve. DPPH scavenging potential was calculated based on the following formula and the $\mathrm{EC}_{50}$ values (concentration at which $50 \%$ free radical scavenged), were also calculated.

$$
\text { Scavenging activity }=\frac{\text { OD of Blank }- \text { OD of Sample }}{\text { OD of Blank }} \times 100 \%
$$

\subsubsection{FRAP assay}

Another antioxidant assay, the ferric reducing antioxidant power assay is based on the transformation of ferric ion $\left(\mathrm{Fe}^{3+}\right)$ to ferrous $\left(\mathrm{Fe}^{2+}\right)^{27} \cdot 0.5 \mathrm{~mL}$ of extract, an equal volume of phosphate buffer $(0.2 \mathrm{M})$, and $1 \%$ potassium ferricyanide $\left[\mathrm{K}_{3} \mathrm{Fe}(\mathrm{CN})_{6}\right]$ were mixed well and incubated for $20 \mathrm{~min}$ at $50^{\circ} \mathrm{C}$. Then $1 \mathrm{~mL}$ trichloroacetic acid (10\%) was added to the mixture and centrifuged immediately for $10 \mathrm{~min}$ at $3000 \mathrm{rpm}$. Subsequently, in $1.5 \mathrm{~mL}$ of the supernatant, equal volume of distilled water and $0.1 \mathrm{~mL}$ of $0.1 \%, \mathrm{FeCl}_{3}$ solution was mixed well. Then the OD was measured at $700 \mathrm{~nm}$ using a UV-Vis spectrophotometer. For standard curve preparation, freshly prepared ascorbic acid solutions of different concentrations $(20-120 \mu \mathrm{g} / \mathrm{mL})$ were used and the $\mathrm{EC}_{50}$ values for every fraction were calculated.

\subsubsection{Total antioxidant capacity (TAC) assay}

The phosphomolybdate assay is widely used for TAC assessment of natural products ${ }^{28}$. The extract fractions $(1 \mathrm{~mL} ; 100 \mu \mathrm{g} / \mathrm{mL})$ were mixed with the reagent mixture $(4 \mathrm{~mL} ; 0.60 \mathrm{M}$ of sulfuric acid, $4 \mathrm{mM}$ of ammonium molybdate, and $28 \mathrm{mM}$ sodium phosphate) and incubated at $95^{\circ} \mathrm{C}$ for $90 \mathrm{~min}$. The optical density was recorded at $695 \mathrm{~nm}$ using the UV-Vis spectrophotometer. The TAC of the extracts was calculated from the standard curve, prepared using ascorbic acid, and expressed as ascorbic acid equivalence (AAE).

\subsection{In vitro antibacterial susceptibility test: agar well diffusion method}

The in vitro antibacterial susceptibility test of the different extracts of $C$. citrinus was evaluated through the agar well diffusion method, based on the diameter of the zone of 
inhibition $^{29}$. This in vitro microbial growth inhibitory activity of $C$. citrinus was determined against four human pathogenic bacteria, two of them were gram-positive such as Bacillus megaterium (MTCC 2412) and Bacillus cereus (MTCC 1272) and two were gram-negative such as Staphylococcus aureus (MTCC 9542) and Enterobacter aerogenes (MTCC 111). All bacterial strains were obtained as pure culture from the Parasitology and Microbiology Research Laboratory, Department of Zoology, The University of Burdwan, where they were maintained as stock strains in glycerol at $-80^{\circ} \mathrm{C}$.

For the antimicrobial assay, the pure cultures of the four above mentioned bacterial strains were inoculated separately on the sterilized nutrient broth media and incubated in BOD shaker incubator at $32 \pm 2^{\circ} \mathrm{C}$ temperature for $24 \mathrm{~h}$. Sterilized plates containing Muller Hinton agar were prepared and $10 \mu \mathrm{L}$ bacterial suspension was spread evenly over them, with a sterile cotton-glass hockey stick, from their standardized dilution of $10^{8}$ colony-forming unit $(\mathrm{CFU}) / \mathrm{mL}$ of the microbes. Wells of $6 \mathrm{~mm}$ (diameter) were made with the help of Cork borer and from 1 $\mathrm{mg} / \mathrm{mL}$ concentration of all the extract fractions $100 \mu \mathrm{L}(\equiv 100 \mu \mathrm{g})$ were added in the separate wells. Tetracycline $(30 \mu \mathrm{g} / \mathrm{disc})$ was used as a positive control and DMSO $(0.1 \%)$ was used as a negative control. The plates were incubated in the BOD incubator for the next $24 \mathrm{~h}$ and then the zone of inhibitions was recorded from at least three of the replicas.

\subsection{Phytochemical analysis}

\subsubsection{Qualitative phytochemical analysis}

The qualitative phytochemical analyses of SEF and the CAQ were done following the standard procedures as described by Harborne ${ }^{30}$ and Trease et al. ${ }^{31}$ with slight modifications.

\subsubsection{Quantitative analysis}

\subsubsection{The total phenolics content (TPC)}

The total phenolics content of the CAQ and SEF of $C$. citrinus leaves was estimated with Folin-Ciocalteu's phenol reagent (FCP) and expressed as tannic acid equivalent (TAE) per mg of dried extract $(\mathrm{DE})^{32}$.

At first, $100 \mu \mathrm{L}(\equiv 100 \mu \mathrm{g})$ of the test sample was taken in each test tube and then $900 \mu \mathrm{L}$ distilled water was added to make the total volume of $1 \mathrm{~mL}$. Then $500 \mu \mathrm{L}$ of FCP (1 N) was added in each tube and mixed properly. After that, $2.5 \mathrm{~mL}$ of sodium carbonate $\left(\mathrm{Na}_{2} \mathrm{CO}_{3}\right)$ 
solution (20\%) was added and mixed thoroughly. Then they were kept in dark for 40 min at room temperature $\left(25 \pm 2^{\circ} \mathrm{C}\right)$. After that, the OD was recorded at $725 \mathrm{~nm}$ using the UV-Vis spectrophotometer. The total phenolics content was estimated comparing the OD with the standard curve of tannic acid, prepared from varying range of concentrations $(5-50 \mu \mathrm{g} / \mathrm{mL})$. This assay was done in triplicate for each sample and the results were expressed as Mean \pm SEM.

\subsubsection{The total flavonoids content (TFC)}

The total flavonoids content of all the extracts was estimated with aluminum chloride $\left(\mathrm{AlCl}_{3}\right)$ method and expressed as quercetin equivalent $(\mathrm{QE})$ per mg of dried extract (DE) ${ }^{33}$.

At first, $0.5 \mathrm{~mL}$ of the test sample was taken in each test tube and then $1 \mathrm{~mL}$ of distilled water was added. After that $1.5 \mathrm{~mL}$ of $5 \%$ sodium nitrite solution $\left(\mathrm{NaNO}_{2}\right)$ and $0.15 \mathrm{~mL}$ of $10 \%$ $\mathrm{AlCl}_{3}$ were added. This mixture was allowed to settle down for $6 \mathrm{~min}$ and then $1 \mathrm{~mL}$ of $1 \mathrm{M}$ sodium hydroxide $(\mathrm{NaOH})$ was mixed to all. After that water was added to the solution until the final volume reached $5 \mathrm{~mL}$. Their OD was recorded at $510 \mathrm{~nm}$ using the above mentioned UVVis spectrophotometer, and from that, the flavonoids contents of the extracts were estimated comparing with the standard curve of quercetin. The range of quercetin concentrations for the standard curve preparation was from $10 \mu \mathrm{g}$ to $500 \mu \mathrm{g} / \mathrm{mL}$. This assay was also done in triplicate for each sample and results were expressed as Mean \pm SEM.

\subsection{Statistical analysis}

All data were expressed as Mean \pm SEM using Origin 8.0 Software and $\mathrm{EC}_{50}$ values were determined by statistical software. The significance of differences among the groups was calculated statistically by one-way analysis of variance (ANOVA) at the confidence level of $95 \%$ $(p \leq 0.05)$ followed by the Post Hoc Tukey test using the Origin 8.0 Software. The correlation of coefficient $(r)$ between the total phenolics and flavonoids content as well as total antioxidant caacity and also with the $\mathrm{EC}_{50}$ values of $\mathrm{DPPH}$ and FRAP assays were performed using Microsoft Office Excel 2007.

\section{Result}

\subsection{In vitro antioxidant assessment}

\subsubsection{DPPH assay}


All the data indicate a positive correlation between the concentration of the extracts and their free radical scavenging activities. Here, the AQF showed the maximum free radical scavenging activity amongst all test extracts, which doesn't vary significantly from the standard $(p \leq 0.05)$ in one way ANOVA. Its $\mathrm{EC}_{50}$ value $(43.88 \pm 3.07 \mu \mathrm{g} / \mathrm{mL})$, the required concentration to scavenge half of the free radicals, is nearly twice than that of the standard ascorbic acid $(22.42 \pm 0.74 \mu \mathrm{g} / \mathrm{mL})$. All the extracts except PEF and CHF showed significant efficiency in free radical scavenging activity. The comparative $\mathrm{EC}_{50}$ values of $\mathrm{DPPH}$ scavenging activities of the remaining extracts revealed as 2.6, 3.4, and 3.7 times higher than the standard's value respectively for EAF, MEF, and CAQ fractions (Table 1).

Table 1: Different in vitro antioxidant assays, total phenolics, and total flavonoids contents of the different extracts

\begin{tabular}{|c|c|c|c|c|c|}
\hline \multirow{2}{*}{$\begin{array}{c}\text { Extract } \\
\text { Fractions }\end{array}$} & DPPH assay & $\overline{\text { FRAP assay }}$ & \multirow{2}{*}{$\begin{array}{c}\text { TAC }(\mu \mathrm{g} \\
\text { AAE/mg DE })\end{array}$} & \multirow{2}{*}{$\begin{array}{c}\text { TPC }(\mu \mathrm{g} \text { TAE } \\
/ \mathrm{mg} \mathrm{DE})\end{array}$} & \multirow{2}{*}{$\begin{array}{c}\text { TFC }(\mu \mathrm{g} \\
\mathrm{QE} / \mathrm{mg} \mathrm{DE})\end{array}$} \\
\hline & \multicolumn{2}{|c|}{$\mathrm{EC}_{50}$ values $(\mu \mathrm{g} / \mathrm{mL})$} & & & \\
\hline $\mathrm{AA}$ & $22.42 \pm 0.7$ & $28.54 \pm 2.3$ & - & - & - \\
\hline PEF & $147.99 \pm 4.8$ & $653.19 \pm 5.8$ & $149.22 \pm 5.1$ & $37.37 \pm 6.3$ & $264.84 \pm 22.6$ \\
\hline $\mathrm{CHF}$ & $512.02 \pm 14.3$ & $1188.21 \pm 11.8$ & $59.06 \pm 2.2$ & $36.85 \pm 2.1$ & $110.55 \pm 11.3$ \\
\hline EAF & $58.92 \pm 0.9$ & $142.62 \pm 2.7$ & $259.24 \pm 6.9$ & $179.98 \pm 10.0$ & $232.95 \pm 13.9$ \\
\hline $\mathrm{MEF}$ & $76.49 \pm 2.4$ & $182.50 \pm 2.4$ & $251.40 \pm 5.9$ & $207.40 \pm 6.8$ & $226.77 \pm 4.8$ \\
\hline $\mathrm{AQF}$ & $43.88 \pm 3.0$ & $88.74 \pm 3.5$ & $441.48 \pm 12.8$ & $308.21 \pm 5.9$ & $516.70 \pm 3.5$ \\
\hline CAQ & $83.28 \pm 3.4$ & $233.09 \pm 3.4$ & $241.33 \pm 1.1$ & $158.18 \pm 5.5$ & $193.13 \pm 3.3$ \\
\hline
\end{tabular}

Data are expressed as Mean \pm SEM. The level of confidence was considered at $95 \%(p \leq 0.05)$ by ANOVA for the determination of differences among the groups followed by the Post hoc Tukey test. $\mathrm{EC}_{50}$ - effective concentration to do the 50\% effect; DPPH- 1,1-diphenyl-2-picrylhydrazyl; FRAP- ferric ion reducing antioxidant power; TAC- total antioxidant capacity; AAE- ascorbic acid equivalents; DE- dry extract; TPC- total phenolics content; TAE- tannic acid equivalents; TFC- total flavonoids content; QE- quercetin equivalents, PEF- petroleum ether fraction; CHFchloroform fraction; EAF- ethyl acetate fraction; MEF- methanol fraction; AQF- aqueous fraction; CAQ- crude aqueous; SEM- standard error of the mean.

\subsubsection{FRAP assay}


Like DPPH assay, the result of FRAP assay also indicates that AQF is the best depository of antioxidant phytochemicals. The half-maximum effective ferric ion reducing power concentrations $\left(\mathrm{EC}_{50}\right)$ for standard ascorbic acid $(28.54 \pm 2.3 \mu \mathrm{g} / \mathrm{mL})$ was found to be one-third of the most effective fraction, AQF $(88.74 \pm 3.5 \mu \mathrm{g} / \mathrm{mL})$. The order of reduction capacity of ferric ion $\left(\mathrm{Fe}^{3+}\right)$ to ferrous $\left(\mathrm{Fe}^{2+}\right)$ of the remaining extracts were determined as EAF> MEF> CAQ> $\mathrm{PEF}>\mathrm{CHF}$, which reflects in their gradually increasing $\mathrm{EC}_{50}$ values respectively as $142.6 \pm 2.8$, 182.5 $\pm 2.5,233.1 \pm 3.4,653.2 \pm 5.8,1188.2 \pm 11.8 \mu \mathrm{g} / \mathrm{mL}$ (Table 1).

\subsubsection{The total antioxidant capacity (TAC) assay}

This data also indicates the differential TAC of the SEF and CAQ, and the decreasing order of TAC of them was established as $\mathrm{AQF}>\mathrm{EAF}>\mathrm{MEF}>\mathrm{CAQ}>\mathrm{PEF}>\mathrm{CHF}$, which is again similar to the previous order of $\mathrm{EC}_{50}$ values. The $\mathrm{AQF}$ showed a significantly higher $(P \leq 0.05$, analyzed by one way ANOVA, followed by Post Hoc Tukey test) antioxidant capacity (441.5 $\pm 12.8 \mathrm{mg} \mathrm{AAE} / \mathrm{g}$ dried extract) than all other extract fractions (Table 1).

\subsection{In vitro antibacterial susceptibility test}

For antibacterial activity assessment, the above-mentioned extracts were tested through the agar well diffusion method and found to have varying antimicrobial properties. Data designate the PEF as the most effective extract fraction against both the gram-positive and negative bacterial strains, followed by CHF and EAF. 29.0 $\pm 1.7,25.33 \pm 1.9,23.0 \pm 1.2$ and $22.0 \pm 1.5 \mathrm{~mm}$ zones of inhibition were formed by only $100 \mu \mathrm{g}$ of PEF against B. megaterium, $B$. cereus, S. aureus, and E. aerogenes respectively (Table 2, Figure 1). The CHF (100 $\mu \mathrm{g})$ showed $23.67 \pm 2.02,24.33 \pm 1.8,21 \pm 1.7$ and $22.38 \pm 2.02 \mathrm{~mm}$ zones of inhibition against $B$. megaterium, B. cereus, S. aureus and E. arogens respectively. 15 to $17.33 \mathrm{~mm}$ zones of inhibition were made by the same dose of EAF against these bacteria. But other three extract fractions MEF, AQF, and CAQ didn't have any antibacterial effect against all of the used bacterial strains. Also the negative control i.e. DMSO had not shown any zone of inhibition in any culture. The standard antibiotic tetracycline, which was used to compare the effectiveness of the extract fractions, had approximately 40 and $27 \mathrm{~mm}$ zone of inhibition against gram-positive and negative bacterial strains respectively. 
Table 2: Antibacterial effects (zone of inhibition) of the test extracts, after $24 \mathrm{~h}$ of incubation

\begin{tabular}{ccccc}
\hline Extract fractions & \multicolumn{4}{c}{ Diameter of zone of inhibition in mm (Mean \pm SEM) } \\
\cline { 2 - 5 } & B. megaterium & B. cereus & S. aureus & E. aerogenes \\
\hline CON-DMSO & $00.0 \pm 00.0$ & $00.0 \pm 00.0$ & $00.0 \pm 00.0$ & $00.0 \pm 00.0$ \\
TE & $40.67 \pm 0.88$ & $39.0 \pm 2.08$ & $26.33 \pm 2.02$ & $27.60 \pm 1.76$ \\
PEF & $29.0 \pm 1.73$ & $25.33 \pm 1.85$ & $23.0 \pm 1.15$ & $22.0 \pm 1.52$ \\
CHF & $23.67 \pm 2.02$ & $24.33 \pm 1.76$ & $21.0 \pm 1.73$ & $22.33 \pm 2.02$ \\
EAF & $17.0 \pm 1.15$ & $15.0 \pm 1.52$ & $17.33 \pm 2.33$ & $17.33 \pm 2.33$ \\
MEF & $00.0 \pm 00.0$ & $00.0 \pm 00.0$ & $00.0 \pm 00.0$ & $00.0 \pm 00.0$ \\
AQF & $00.0 \pm 00.0$ & $00.0 \pm 00.0$ & $00.0 \pm 00.0$ & $00.0 \pm 00.0$ \\
CAQ & $00.0 \pm 00.0$ & $00.0 \pm 00.0$ & $00.0 \pm 00.0$ & $00.0 \pm 00.0$
\end{tabular}

Data are expressed as Mean \pm SEM. The level of confidence was considered at $95 \%(p \leq 0.05)$ by ANOVA for the determination of differences among the groups followed by the Post hoc Tukey test. $\mathrm{CON}-\mathrm{DMSO}=$ control dimethyl sulfoxide; $\mathrm{TE}=$ tetracycline; $\mathrm{PEF}=$ petroleum ether fraction; $\mathrm{CHF}=$ chloroform fraction; $\mathrm{EAF}=$ ethyl acetate fraction; $\mathrm{MEF}=$ methanol fraction; $\mathrm{AQF}=$ aqueous fraction; $\mathrm{CAQ}=$ crude aqueous; $\mathrm{SEM}=$ standard error of the mean.
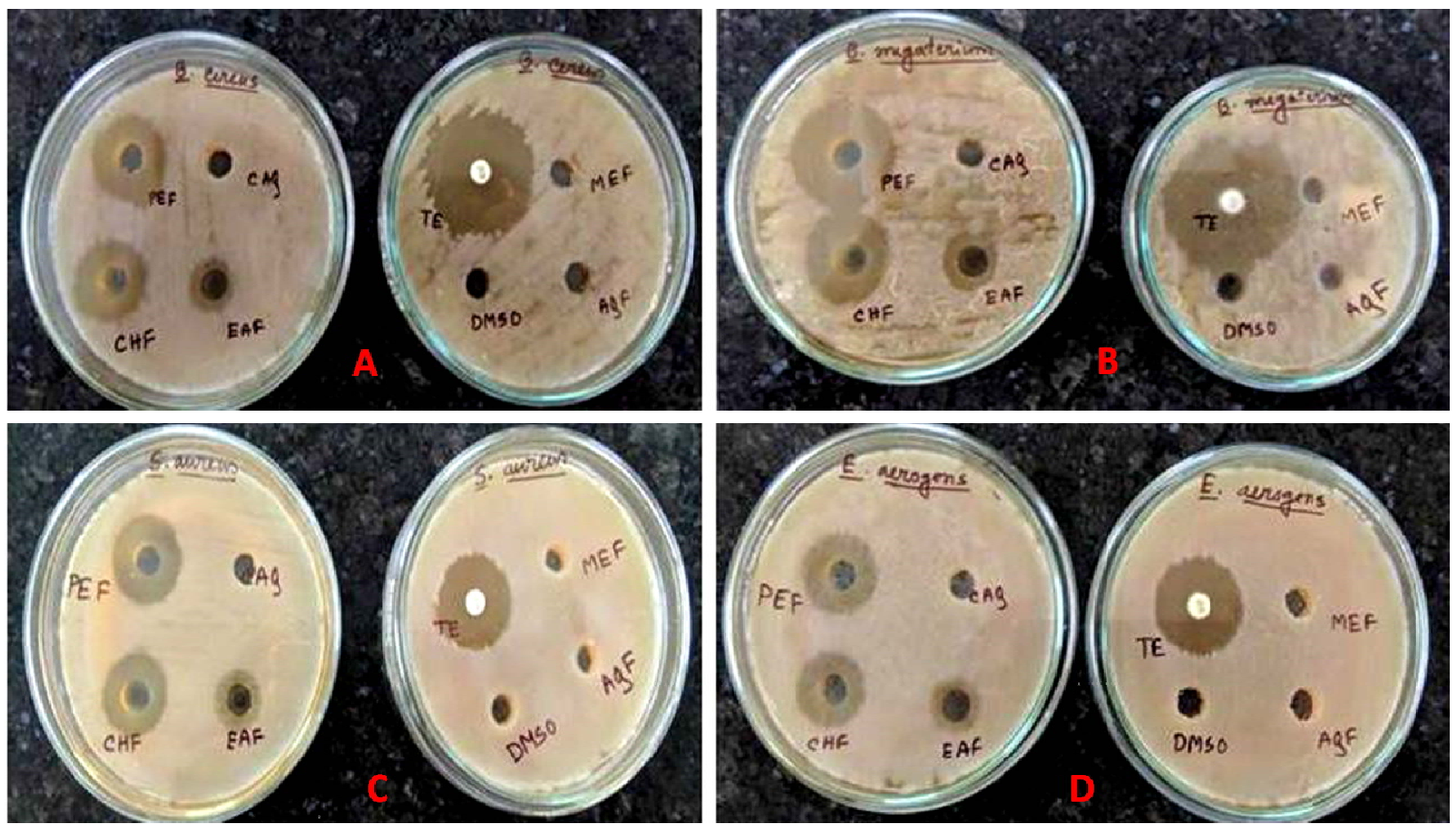

Figure 1: Photographs showing the zone of inhibitions with the successive extract fractions of $C$. citrinus leaves at $24 \mathrm{~h}$ of incubation against gram-positive and gram-negative bacteria. A; Bacillus cereus, B; Bacillus megaterium, C; Stephylococcus aureus, D; Enterobacter aerogenes. 
$\mathrm{PEF}=$ petroleum ether fraction; $\mathrm{CHF}=$ chloroform fraction; $\mathrm{EAF}=$ ethyl acetate fraction; $\mathrm{MEF}=$ methanol fraction; $\mathrm{AQF}=$ aqueous fraction; $\mathrm{CAQ}=$ crude aqueous; $\mathrm{DMSO}=$ dimethyl sulfoxide; $\mathrm{TE}=$ tetracycline.

\subsection{Phytochemical analysis}

\subsubsection{Qualitative phytochemical analysis}

The preliminary phytochemical analyses show the presence of different types of secondary metabolites such as alkaloids, flavonoids, terpenoids, tannins, steroids, carbohydrates, and saponins in varying amounts, but glycosides, phlobatannins, and anthraquinones were absent in any of the extract (Table 3). Steroids were detected in PEF, CHF, and EAF. Terpenoids were detected in all fractions and found comparatively more abundant in MEF, AQF, and CAQ than the others, moderate in PEF and EAF, and detected least in CHF. Alkaloids were detected in PEF, CHF, and MEF. Flavonoids were detected in PEF, EAF, MEF, AQF, and CAQ.Tannins were detected in EAF, MEF, AQF, and CAQ. Carbohydrate and reducing sugars were detected only in the CAQ, MEF and AQF while saponins were detected in CAQ, and AQF.

Table 3: The preliminary phytochemical analysis of the test extracts

\begin{tabular}{|c|c|c|c|c|c|c|c|}
\hline \multirow{2}{*}{\multicolumn{2}{|c|}{$\begin{array}{c}\text { Phytochemicals and } \\
\text { Tests Performed }\end{array}$}} & \multicolumn{6}{|c|}{ Extracts } \\
\hline & & CAQ & $\mathrm{PEF}$ & $\mathrm{CHF}$ & EAF & $\mathrm{MEF}$ & AQF \\
\hline \multirow[t]{3}{*}{ Tannins } & $\mathrm{FeCl}_{3}$ test & + & - & - & + & + & + \\
\hline & Alkaline reagent test & + & - & - & + & + & + \\
\hline & Bromine water test & + & - & - & + & + & + \\
\hline Terpenoids & Kantamreddi et al., 2010 & + & + & + & + & + & + \\
\hline Carbohydrates & Benedict's test & + & - & - & - & + & + \\
\hline \multirow[t]{2}{*}{ Alkaloids } & Mayer's test & - & + & + & - & + & - \\
\hline & Wagner's test & - & + & + & - & - & - \\
\hline \multirow[t]{2}{*}{ Glycosides } & Alkaline reagent test & - & - & - & - & - & - \\
\hline & Fehling test & - & - & - & - & - & - \\
\hline Phlobatannins & Hydrochloric acid test & - & - & - & - & - & - \\
\hline Reducing sugars & Fehling's test & + & - & - & - & + & + \\
\hline Flavonoids & Zinc-HCl test & + & + & - & + & + & + \\
\hline
\end{tabular}




\begin{tabular}{|c|c|c|c|c|c|c|c|}
\hline & Alkaline solution test & + & + & - & + & + & + \\
\hline Steroids & Kantamreddi et al., 2010 & - & + & + & + & - & - \\
\hline Saponins & Froth test & + & - & - & - & - & + \\
\hline Anthraquinones & Borntrager's test & - & - & - & - & - & - \\
\hline
\end{tabular}

'+'= present and '-'= absent. $\mathrm{PEF}=$ petroleum ether fraction; $\mathrm{CHF}=$ chloroform fraction; $\mathrm{EAF}=$ ethyl acetate fraction; $\mathrm{MEF}=$ methanol fraction; $\mathrm{AQF}=$ aqueous fraction; $\mathrm{CAQ}=$ crude aqueous.

\subsubsection{Quantitative analysis}

\section{Total phenolics and flavonoids contents}

The total phenolics and flavonoids contents of the extract fractions of C. citrinus were estimated and data indicate that AQF contains the highest quantity of phenolics $(308.2 \pm 5.9 \mu \mathrm{g}$ $\mathrm{TAE} / \mathrm{mg} \mathrm{DE})$ and flavonoids $(516.7 \pm 3.5 \mu \mathrm{g} \mathrm{QE} / \mathrm{mg} \mathrm{DE})$ (Table 1). The differential total phenolics contents of the extracts are in a decreasing order of AQF> MEF> EAF> CAQ> PEF> $\mathrm{CHF}$ and in the case of total flavonoids, that slightly differs with placing PEF fraction at the second-highest position rather from the second-lowest. The CHF contains the least quantity of both the phytochemicals.

\section{Discussion}

Callistemon citrinus has gained much attention as a folk medicinal reputation for the treatment of various ailments like gastrointestinal pain, respiratory disorder, infectious diseases, etc. and its various beneficial activities including antidiabetic, cardioprotective, and hepatoprotective potentials were explored scientifically ${ }^{14,15,16,17,24,25}$. In this study, we have explored a comparative in vitro antioxidant and antibacterial activities of the crude aqueous and the successive leaf extract fractions. Thus different in vitro free radical scavenging activities like total antioxidant, DPPH and FRAP assays, phytochemicals analysis, along with antibacterial tests were performed.

Out of the six extracts tested here, the last and first fractions of the Soxhlet extraction, i.e. the AQF and PEF have displayed the highest antioxidant and antibacterial activities respectively. The data of DPPH and FRAP assays indicate that the last Soxhlet fraction, AQF, is the best depository of antioxidant phytochemicals amongst all the extract fractions. Though the $\mathrm{EC}_{50}$ values of ascorbic acid for both DPPH and FRAP assays were lower than the most effective 
fraction, AQF, but despite being a mixture of compounds, its required concentration was only thrice to the standard. It is reported that most of the antioxidant compounds responsible for plants bioactivity are mainly phenolics and/or flavonoids which are extracted in polar solvents as the crude extract contains a rich combination of phytochemicals, while a specific fraction of any successive extraction procedure have fewer types of molecules due to their solvent affinity and polarity $6,8,9,10,28$. The differential total antioxidant activity (TAC) of the different organic solventmediated extracts of various medicinal plants were reported due to their variations in phenolics content $^{8,9,28}$. Here also it is clear that the last fraction of the successive extraction procedure, which acts as the most potent antioxidant fraction, is rich in bioactive phytochemicals and extracted with the most polar solvent. An earlier study indicated that the crude leaf methanolic extract of $C$. citrinus and its extract fractions have differential free radical scavenging potentials and that also supports our findings that water is more suitable than petroleum ether for extracting bioactive antioxidant molecules from $C$. citrinus leaf $^{23}$. Recently, through a comparative study, our laboratory reported that the successive leaf aqueous extract fraction of Crinum asiaticum having the highest antioxidant and antibacterial potentials along with the highest phenolics contents ${ }^{8}$.

From over 8000 known flavonoids molecules, polyphenols with $\mathrm{C}_{6}-\mathrm{C}_{3}-\mathrm{C}_{6}$ skeleton, have shown many in vitro multiple biological activities like anticancer, anti-oxidation, antiinflammation, cardiovascular, and antibacterial ${ }^{34}$. Flavonoids and tannins which are phenolics were more or less detected in EAF, MEF, and AQF fractions, which have prominent free radical scavenging and antibacterial actions. There is also other evidence that crude methanolic and ethanolic extracts have more potency to scavenge free radicals than other crude extract or successive extract fractions 5,21 . Another study reported that ketones, terpenoids, aldehyde, hydrocarbons, and other groups also have minor contribution to quench free radicals. Several recent scientific reports indicate that antioxidant activity of various plant extracts are remarkably high and may health-beneficial for us $6,8,10,35,36$. We need to consume a larger amount of antioxidant-rich foods, such as different types of vegetables (pepper leaf, oregano, beans, beetroot, color cabbages, sweet potato, broccoli, carrots, etc.) and various fruits (berries, peach, banana, grapes, apple, pear, etc.), and beverages (tea, coffee, and various fruit juices, etc.) to reduce the probability of deadly diseases related to oxidative stress ${ }^{35,37}$. 
The AQF of $C$. citrinus leaves shows a significantly higher amount of both TFC and TPC than other fractions, which correlates its maximized antioxidant activity and may be reasoned behind it. The TAC of AQF is also the highest of all. Plants produce various types of secondary metabolites such as flavonoids, alkaloids, steroids, terpenoids, etc., which protect plants from microorganisms, herbivores, insects or even other competitive plants that's why a potential antibacterial activity is expected from such extracts. Quantitative phytochemical analysis revealed that PEF contains the second-highest total flavonoids amongst all the extract fractions. Flavonoids under the group phenolics, derived from tyrosine, phenylalanine, and malonate are well-known antioxidants. The chemical structure of phenolic compounds is ideal for free radical quenching due to the presence of hydroxyl groups with aromatic rings. Hydrogen atom or an electron of the hydroxyl group is easy to donate to a free radical and thus creates phenoxy radical intermediates, which are relatively stable than free radicals due to the resonance formation within the benzene ring ${ }^{38}$. There is sufficient literature regarding flavonoids' antibacterial mechanism of action $^{39,40}$. It is reported that flavonoids coat the cells' surfaces and consequently disturb the interactions between the surface of the substratum and bacterial cells ${ }^{41}$. The antibacterial activity of flavonoids can be exerted by killing bacteria directly, synergistically activating antibiotics, and attenuating the bacterial pathogenicity through the combination of inhibitory actions on the nucleic acid synthesis, energy metabolism, cytoplasmic membrane function, attachment and biofilm formation ${ }^{40}$, restrained the synthesis of peptidoglycan and ribosome in the cells of amoxicillin-resistant $E$. coli $^{42}$, inhibiting the efflux pump of $\mathrm{MRSA}^{43}$, inhibiting different kinds of lactamases, key enzymes that disable antibiotics, produced by bacteria ${ }^{44,45}$.

Many scientists explored the antibacterial activity of crude methanolic and ethanolic leaves extract, but here we found that the antibacterial compound(s) were extracted mainly in the non-polar solvents (petroleum ether, chloroform, and ethyl acetate) when successive extraction was done using a Soxhlet apparatus. Phytochemical tests showed that PEF, CHF, and EAF contain steroids, alkaloids, terpenoids, and flavonoids. The Steroids were comparatively more abundant in CHF than PEF but both of them were positive for terpenoids and alkaloids too. It was reported that E. coli is resistant to methanolic and ethanolic extracts of $C$. citrinus and its probable reason is cell membrane permeability or genetic factors ${ }^{24}$, this report supports the present study, all bacterial strains were resistant to MEF, AQF, and CAQ. 
Many studies have revealed that the gram-positive bacteria are more susceptible than gram-negative bacteria due to the absence of gram-negatives' unique outer structure i.e. outer membrane, periplasmic space, high lipopolysaccharide content, high lipid, and lipoprotein content $^{24}$. Both the PEF and CHF show greater efficacy against gram-positive strains than the gram-negative, indicating the effect may be related to the cell membrane permeability. Notable no significant variation in the antimicrobial activities was found in one way ANOVA at the $95 \%$ confidence level $(p \leq 0.05)$, followed by the post hoc Tukey test among the PEF, CHF, and the standard antibiotic, Tetracycline. In the case of gram-negative bacteria, the potency of microbial growth inhibition of PEF and CHF is very much comparable with the tetracycline. These results signify that the potent antimicrobial compounds are mostly extracted through the petroleum ether followed by chloroform and ethyl acetate, which implies their non-polar nature.

Phytochemical analysis indicates that in addition to flavonoids, it may be the alkaloids in phytochemistry which is present in PEF, CHF in a decreasing amount but absent in EAF, though steroid is exclusively present in these three fractions also may responsible too. Phytochemicals exert their antimicrobial effects in different ways; for example, alkaloids intercalate with DNA and inhibit topoisomerase thus blocks DNA synthesis ${ }^{46}$. Another similar work reported where alkaloids of $C$. citrinus showed antibacterial potency against $S$. aureus and $P$. areuginosa through inhibition of ATP-dependant efflux pumps ${ }^{25}$. This pump helps bacteria to prevent the accumulation of drugs or compounds (antibiotics) inside the cells. Another study indicated the essential oils of $C$. citrinus (both leaves and flower) to have in vitro antibacterial activity against B. cereus, E. coli, S. aureus, and S. typhi due to the presence of phenolics and terpenoids (mainly monoterpenoids) ${ }^{47}$. Statistical significant differences are present between vehicle control (DMSO) and all the effective fractions (PEF, CHF and EAF) which nullify the questions of any solvent toxicity.

There are strong positive correlations between consumption of polyphenolics enrich foodstuff and lowering the incidence of degenerative chronic diseases such as cancer, arthritis, renal diseases, heart disease, inflammations, neural disorders like brain dysfunction and eye diseases (cataracts) which are related to oxidative stress ${ }^{48}$. Phenolics and flavonoids are the secondary metabolites, present in almost all plants at various levels and positively correlate each other's quantity $^{8}$, here too. A positive correlation exists between the reduced incidence of cancer and the regular uptake of phenolics-rich plant products ${ }^{49}$. Correlation analysis indicates linear 
negative correlations between the total phenolics or flavonoids contents and $\mathrm{EC}_{50}$ values of DPPH or FRAP assay and their linear positive correlations $(r=0.956$ and $0.878, P=0.002$ and 0.026 respectively) with the total antioxidant capacity. Thus it was concluded that phenolics and flavonoids may contribute respectively 95.6 and $74.9 \%$ of the total antioxidant capacities. Such a strong positive relationship between this phytochemicals' quantity and in vitro free radical quenching activity of the leaf extract fractions of Manilkara hexandra (Roxb.) has already been established ${ }^{6}$. Also, these types of correlations are established between the antioxidant activities and the total phenolics and flavonoids contents of many different plants like Sonchus arvensis ${ }^{50}$, Ampelocissus latifolia ${ }^{9}$, and Crinum asiaticum ${ }^{8}$.

\section{Conclusion}

Callistemon citrinus leaf extracts contain various types of phytochemicals which were fractionated through solvent partitioning and polarity gradient. Its successive extract fractions have varying degrees of in vitro antioxidant and antibacterial activities. The most polar aqueous fraction of the successive extract fractions exhibited the highest antioxidant activities along with the highest level of total phenolics and flavonoids contents and they were also found to be correlated positively. On the other hand, the most non-polar petroleum ether fractionation showed the highest antibacterial potential and also contains the second-highest flavonoid contents amongst all the extract fractions. Thus, aqueous extract fraction, AQF, from C. citrinus leaf may be considered as a good source of natural antioxidants and the petroleum ether extract fraction, PEF, as a natural source of antibacterial agents that might be useful against oxidative stress-related diseases and bacterial infection respectively. Thus, these extract fractions might have therapeutic and industrial importance. A further elaborate investigation is needed to explore the active principle(s), mechanism action, dose optimization, and toxic profile before using them as prophylaxis medication mainly in livestock industries.

\section{Acknowledgments}

The authors acknowledge the financial support of SVMCM The Government of West Bengal as the Swami Vivekananda Scholarship for M.Phil. and Ph.D., CSIR and UGC fellowship and the DST-FIST, DST-PURSE, and UGC-DRS-sponsored infrastructural facilities in the Department of Zoology. Prof. A. Mukherjee has kindly authenticated the plant species. 
Authors express gratitude to Prof. Soumendranath Chatterjee, Department of Zoology, The University of Burdwan, for extending microbial culture facility and generous supply of bacterial strains.

\section{Conflict of Interest statement}

The authors declare that they have no conflict of interest.

\section{Authors Contribution}

Poulomi Ghosh: Investigation, data curation, Draft manuscript writing; Souren Goswami: Investigation: Sujit Roy: Investigation; Ria Das: Investigation: Tista Chakraborty: Investigation; Sanjib Ray: Conceptualization, Investigation, data analysis and validation, final manuscript writing and editing.

\section{References}

1. Halliwell, B., Gutteridge, J.M.C., 2006. Free Radicals in Biology and Medicine, Ed 4. Clarendon Press, Oxford.

2. Vijg, J., 2000. Somatic mutations and aging: a re-evaluation. Mutat Res. 447(1), 117-135.

3. Valko, M., Rhodes, C.J., Moncol, J., Izakovic, M., 2006. Free radicals, metals and antioxidants in oxidative stress-induced cancer. Mini- review. Chem. Biol. Interact. 160, 140.

4. Rahman, T., Hosen, I., Islam, M.M.T., Shekhar, H.U., 2012. Oxidative stress and human health. Adv. Biosci. Biotechnol. 3, 997-1019.

5. Jamzad, M., Kazembakloo, A., Tehrani, D.A., Rostami, F., 2014. Essential oil composition and antioxidant activity of hydromethanolic extract from the flowers, leaves and stems of Callistemon citrinus (Curtis) Skeels. Indian J Nat Prod Resour. 5, 308-312.

6. Dutta, S., Ray, S., 2015. Evaluation of in vitro free radical scavenging activity of leaf extract fractions of Manilkara hexandra (Roxb.) Dubard in relation to total phenolic contents. Int. J. Pharm. Pharm. Sci. 7(10), 296-301.

7. Goswami, S., Ray, S., 2017. Relative total phenolics content, 1,1-diphenyl picrylhydrazyl free radical scavenging and total antioxidant potentials of seven Indian medicinal plant parts' aqueous extracts. Int. J. Pharm. Bio Sci., 8, 283-291. https:// doi.org/10.22376/jpbs.2017.8.2.p283-291. 
8. Goswami, S., Das, R., Ghosh, P., Chakraborty, T., Barnam, A., Ray, S., 2020. Comparative antioxidant and antimicrobial potentials of leaf successive extract fractions of poison bulb, Crinum asiaticum L. Ind Crop Prod. https://doi.org/10.1016/j.indcrop.2020.112667.

9. Chaudhuri, A., Ray, S., 2020. In vitro free radical scavenging activities of aerial parts' aqueous extract and extract fractions of Ampelocissus latifolia (Roxb.) Planch. in relation to total phenolics and flavonoid contents. J. King Saud Univ Sci. 32(1), 732-739. (https://doi.org/10.1016/j.jksus.2018.12.006.)

10. Dutta, S., Ray, S., 2020. Comparative assessment of total phenolic content and in vitro antioxidant activities of bark and leaf methanolic extracts of Manilkara hexandra (Roxb.) Dubard. Int J. King Saud Univ. Sci. 32(1), 643-647. (https://doi.org/10.1016/j.jksus.2018.09.015.)

11. Sha, S.H., Schacht, J., 1999. Stimulation of free radical formation by aminoglycoside antibiotics. Hear Res. 128(1-2), 112-8. https://doi.org/10.1016/s0378-5955(98)00200-7.

12. Radulovi, N.S., Blagojevi, P.D., Pali, R.M., 2010. Comparative study of the leaf volatiles of Arctostaphylos uva-ursi (L.) Spreng. and Vaccinium vitis-idaea L. (Ericaceae). Molecules. 15(9), 6168-6185.

13. Goyal, P.K., Jain, R., Jain, S., Sharma, A., 2012. A Review on biological and phytochemical investigation of plant genus Callistimon. Asian Pac J Trop Biomed. 2(3), 1906-1909.

14. Netala, S.I., Penmetsa, R.E., Nakka, S.N., Polisetty, B.L., 2015. Pharmacognostic study of Callistemon citrinus L. bark. Int J Pharm Pharm Sci. 7(1), 427-430.

15. Kumar, S., Kumar, V., Prakash, O., 2011. Antidiabetic, hypolipidemic and antioxidant activities of Callistemon lanceolatus leaves extract. J. Herbs Spices Med. Plants. 17, 144.

16. Firoz, M., Bharatesh, K., Nilesh, P., Vijay, G., Tabassum, S., Nilofar, N., 2011. Cardioprotective activity of ethanolic extract of Callistemon lanceolatus leaves on doxorubicin-induced cardiomyopathy in rats. Bangladesh J. Pharmacol. 6, 38.

17. Jain, A.K., Dubey, S.K., Sikarwar, M.S., Jain, S.K., 2007. Hepatoprotective activity of methanolic extract of leaves of Callistemon lanceolatus. Int. J. Plant Sci. 2, 185.

18. Lee, H.K., Lee, H.B., Kim, C.S., Ahn, Y.J., 2004. Anti Helicobacter pylori activity of methanol extracts from Korean native plant species in Jeju Island. Agric. Chem. Biotechnol. 47, 916. 
19. Niaz, A., Shah, S.W., Ahmad, B., 2011. Calcium channel blocking activity of fruits of Callistemon citrinus. J. Chem. Soc. Pakisthan. 33, 245.

20. Kim, J.H., Byun, J.C., Bandi, A.K.R., Hyun, C.G., Lee, N.H., 2009. Compounds with elastase inhibition and free radical scavenging activities from Callistemon lanceolatus. J. Med. Plants Res. 3, 914.

21. Farhana, A., Mohammad, S.R., 2016. Preliminary assessment of free radical scavenging, thrombolytic and membrane stabilizing capabilities of organic fractions of Callistemon citrinus (Curtis.) skeels leaves. BMC. Complement Altern. Med. 16, 247.

22. Radulovic, N.S., Randjelovic, P.J., Stojanovic, N.M., Cakic, N.D., Bogdanovic, G.A., Zivanovic, A.V., 2015. Aboriginal bush foods: A major phloroglucinol from Crimson Bottlebrush flowers (Callistemon citrinus, Myrtaceae) displays strong antinociceptive and antiinflammatory activity. Food Res Int. 77, 280-289.

23. Ahmed, F., Rahman, M.S., 2016. Preliminary assessment of free radical scavenging, thrombolytic and membrane stabilizing capabilities of organic fractions of Callistemon citrinus (Curtis.) skeels leaves. BMC. Complement Altern. Med. 16(247), 1-8.

24. Seyydnejad, S.M., Niknejad, M., Darabpoor, I., Motamedi, H., 2010. Antibacterial activity of hydroalcoholic extract of Callistemon citrinus and Albizia lebbeck. Am. J. Appl. Sci.. 7(1), 13-16.

25. Mabhiza, D., Chitemerere, T., and Mukanganyama, S., 2016. Antibacterial properties of alkaloid extracts from Callistemon citrinus and Vernonia adoensis against Staphylococcus aureus and Pseudomonas aeruginosa. Int. J. Med. Chem. 1-7.

26. Brand-Willims, W., Cuvelier, M.E., Berset, C., 1995. Use of free radical method to evaluate antioxidant activity. Lebenson. Wiss. Technol. 28(1), 25-30.

27. Oyaizu, M., 1986. Studies on products of browning reactions: antioxidative activities of products of browning reaction prepared from glucosamine. J. Acad. Nutr. Diet. 44, 307315.

28. Umamaheswari, M., Chatterjee, T.K., 2008. In vitro antioxidant activities of the fractions of Coccinia grandis L. leaf extract. Afr. J. Tradit. Complement Altern. Med. 5(1), 61-73. 
29. Brown, A., 2004. Benson's Microbiological applications: laboratory manual in general microbiology, MCMGraw-Hill Science. $9^{\text {th }}$ edition, p.35.

30. Harborne, J.B., 1973. Phytochemical Methods. Chapman and Hall Ltd, London, p.49-188.

31. Trease, G.E., Evans, W.C., 1989. Trease and Evans' Pharmacognosy.13th ed. Bailliere Tindall Ltd., Philadelphia, London, p. 832.

32. Makkar, H.P.S., Blummel, M., Borowy, N.K., Becker, K., 1993. Gravimetric determination of tannins and their correlations with chemical and protein precipitation methods. J. Sci. Food Agric. 61, 161-165.

33. Chang, C., Yang, M., Wen, H., Chern, J., 2002. Estimation of total flavonoid content in propolis by two complementary colorimetric methods. J. Food Drug Anal. 10(3), 178-182.

34. Bhattacharya, S., 2011. Are we in the polyphenols era? Pharmacognosy. Res, 3(2), 147-147.

35. Fu, L., Xu, B.T., Xu, X.R., Gan, R.Y., Zhang, Y., Xia, E.Q., Li, H.B., 2011. Antioxidant capacities and total phenolic contents of 62 fruits. Food Chem. 129(2), 345-350.

36. Ayoola, G.A., Sofidiya, T., Odukoya, O., Coker, H.A.B., 2008. Phytochemical screening and free radical scavenging activity of some Nigerian medicinal plants. Int. J. Pharm. Pharm. Sci. 8, 133-136.

37. Manganaris, G.A., Goulas, V., Vicente, A.R., Terry, L.A., 2014. Berry antioxidants: small fruits providing large benefits. J. Sci. Food Agric. 94(5), 825-833.

38. Rice-Evans, CA., Miller, NJ., Paganga, G., 1996. Structure-antioxidant activity relationships of flavonoids and phenolic acids. Free Radic Biol Med, 20, 933-956.

39. Xie, Y., Yang W., Tang F., Chen X., Ren L., 2014. Antibacterial Activities of Flavonoids: Structure-Activity Relationship and Mechanism. Curr Med Chem. 22, 132-149.

40. Cushnie, T.P.T., Lamb, A.J., 2011. Recent advances in understanding the antibacterial properties of flavonoids. Int. J. Antimicrob. Agents. 38(2), 99-107.

41. Wang, Y., Lee, S. M., Dykes, G. A., 2013. Potential mechanisms for the effects of tea extracts on the attachment, biofilm formation and cell size of Streptococcus mutans. Biofouling. 29(3), 307-318.

42. Eumkeb, G., Siriwong, S., Phitaktim, S., Rojtinnakorn, N., Sakdarat, S., 2012. Synergistic activity and mode of action of flavonoids isolated from smaller galangal and amoxicillin 
combinations against amoxicillin-resistant Escherichia coli. J. Appl. Microbiol. 112(1), 5564.

43. Roccaro, A. S., Blanco, A. R., Giuliano, F., Rusciano, D., Enea, V., 2004. Epigallocatechingallate enhances the activity of tetracycline in staphylococci by inhibiting its efflux from bacterial cells. Antimicrob Agents Chemother. 48(6), 1968-1973.

44. Tenover, F. C., 2006. Mechanisms of antimicrobial resistance in bacteria. Am J Infect Control. 34(5), S3-S10.

45. Daglia, M., 2012. Polyphenols as antimicrobial agents. Curr Opin Biotechnol. 23(2), 174181.

46. Bonjean, K., De Pauw-Gillet, M.C., Defresne, M.P., Colson, P., Houssier, C., Dassonneville, L., Bailly, C., Greimers, R., Wright, C., Quentin-Leclercq, J., Tits, M., Angenot, L., 1998. The DNA intercalating alkaloid cryptolepine interferes with topoisomerase II and inhibits the primarily DNA synthesis in B16 melanoma cells. Biochemistry. 37, 5136-5146. https://doi.org/10.1021/bi972927q.

47. Larayetan, R.A., Okoh, O.O., Sadimenko, A., Okoh, A.I., 2017. Terpene constituents of the aerial parts, phenolic contents, antibacterial potential, free radical scavenging and antioxidant activity of Callistemon citrinus (Curtis) Skeels (Myrtaceae) from Eastern Cape Province of South Africa. BMC Complement Altern Med. 17, 292-296.

48. Kris-Etherton, P.M., Hecker, K.D., Bonanome, A., Coval, S.M., Binkoski, A.E., Hilpert, K.F., 2002. Bioactive compounds in foods: their role in the prevention of cardiovascular disease and cancer. Am. J. Med. Stud. 113, 71-88.

49. Hollman, P.C.H., Katan, M.B., 1999. Dietary flavonoids: intake, health effects and bioavailability. Food. Chem. Toxicol. 37(9-10), 937-942.

50. Khan, R.A., 2012. Evaluation of flavonoids and diverse antioxidant activities of Sonchus arvensis. BMC Chem. 6, 126. 